\title{
Pendidikan Islam Masa Rasulullah dan Eksistensi Kuttab serta Masjid dalam Pengembangan Pendidikan Islam
}

\author{
Al Firman Yusra ${ }^{1}$, Zulmuqim $^{2}$ \\ ${ }^{12}$ Pascasarjana Universitas Islam Negeri Imam Bonjol Padang, Indonesia \\ Corresponding Author, email: alfirman847@gmail.com
}

\begin{abstract}
Islamic education system refers to the value of Islam. Islamic education foundation located in attitude or outlook on life itself. Which Islam considers life is not an end of all but ground to achieve spiritual goals after life. At the time of the prophet, Islamic education implemented in two periods, Mecca period and Medina period. Mecca period as the initial construction phase of Islamic education and based in Makkah, and Medina period as the center of Islamic learning and activities. The existence of kuttab and mosques aso affected the development of Islamic education. Where Kuttab and Mosque were the start of existing institutions such as madrassa and school and Islamic collages.
\end{abstract}

Keywords: Education of Islam, the Makkah and Madina, Kuttab and Mosque.

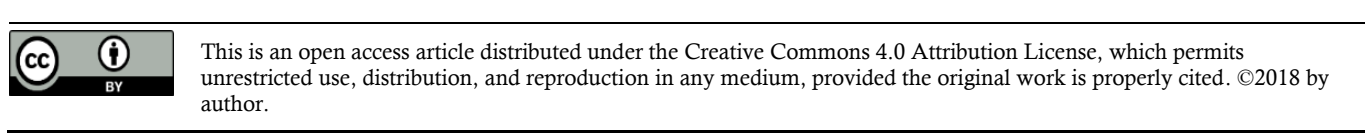

\section{Pendahuluan}

Pendidikan pada hakekatnya muncul sejak diciptakannya manusia, karena manusia itulah yang menjadi obyek utama dari pendidikan di samping juga sebagai subyek. Dalam kenyataan, manusia sangat membutuhkan pendidikan karena ia tidak bisa berkembang dan mengembangkan kebudayaannya secara sempurna apabila tidak ada pendidikan. Dengan demikian dapat dikatakan bahwa eksistensi pendidikan merupakan salah satu syarat yang mendasar bagi meneruskan dan mengekalkan kebudayaan manusia. Namun fungsi pendidikan tidak hanya sebatas meneruskan dan mengekalkan kebudayaan, tetapi lebih dari itu pendidikan berupaya menyesuaikan dan mengembangkan kebudayaan baru secara proporsional dan dinamis. Pendidikan menempati posisi yang sangat sentral dan strategis dalam membangun kehidupan sosial dan memposisikan manusia dalam kehidupan secara tepat(B, 2013).

Dalam sejarah, pendidikan Islam sebagai suatu sub sistem dari sistem pendidikan pada umumnya baru dikenal sesudah diutusnya Muhammad SAW. sebagai rasul. Sistem pendidikan Islam mengacu kepada nilai-nilai Islam. Karena itu, sistem pendidikan Islam menciptakan perbedaan yang mendasar dengan sistem pendidikan pada umumnya (modern) baik dari Timur maupun dari Barat. Perbedaan yang menonjol antara keduanya terletak pada sikap atau pandangan terhadap hidup itu sendiri, dimana Islam menganggap hidup bukan suatu akhir dari segalanya tetapi alasan untuk mencapai tujuan-tujuan spritual setelah hidup. Sedangkan dalam pandangan Barat, kenikmatan menjadi tujuan akhir hidup yang didukung oleh materi yang berkecukupan (Suwito \& fauzan, 2008).

Berbicara tentang Sejarah Pendidikan Islam, pada hakikatnya tidak terlepas dari sejarah Islam. Periodisasi sejarah pendidikan Islam dapat dikatakan berada dalam periode sejarah Islam itu sendiri. Secara garis besarnya, Harun Nasution membagi sejarah Islam ke dalam tiga periode, yaitu periode klasik, pertengahan, dan modern(Nasution, 2012). Kemudian perinciannya dapat dibagi lima masa, yaitu:

1. Masa hidupnya Nabi Muhammad saw (571-632 M)

2. Masa Khulafaur Rasyidin (632-661 M) 
3. Masa Umayyah di Damsik (661-750 M).

4. Masa Abbasiyah di Bagdad (750-1250 M).

5. Masa runtuhnya kekuasaan khalifah di Baghdad tahun $1250 \mathrm{M}$. sampai sekarang (Zuhairini \& dkk, 1986).

Dalam artikel yang penulis sajikan ini memfokuskan pada perkembangan Pendidikan Islam masa Rasulullah SAW. Sejalan dengan jurnal yang di tulis Mahfud Ifendi, 2021, Pendidikan Islam Masa Rasulullah Saw Periode Madinah: Strategi, Materi, Dan Lembaga Pendidikan. Hamim Hafiddin, 2015,Pendidikan Masa Islam Masa Rasulullah. Chaeruddin, 2013,Pendidikan Islam Masa Rasulullah Saw.Mahfud Ifendi, 2020, Masa Pembinaan Pendidikan Islam: Telaah Kritis Pendidikan Islam Masa Rasulullah Saw Periode Makkah. Saddam Husein, Pola Pendidikan Islam Masa Rasulullah Saw.Suriadi, Pendidikan Islam Masa Rasulullah Saw. Mahfud Ifendi, 2021, Kuttab Dalam Lintas Sejarah: Dari Masa Kejayaan pendidikan Islam. Kajian jurnal ini diharapkan akan bermanfaat bagi penambahan referensi kajian pendidikan Islam.

\section{Metode}

Jenis penelitian ini adalah penelitian kepustakaan (library research).Penelitian kepustakaan adalah penelitian yang dilakukan di perpustakaan atau museum terhadap bahan-bahan bukubuku, majalah atau dokumen lainnya yang ada (Amar, 2007). Penelitian kepustakaan (Library Research) sesuai dengan permaslahan yang dibahas dengan langkah-langkah operasional, mengumpulkan, membaca, meneliti, menganalisis, menginterpretasikan dan manarik kesimpulan dari datap-data yang bersifat informasi yang sesuai dengan pembahasan.

Dalam hal ini penulis menggunakan buku utama (primer) adalah buku karangan Ramayulis, Sejarah Pendidikan Islam: Napaktilas Perubahan Konsep, Filsafat, Dan Metodologi Pendidikan Islam Dari Era Nabi Saw Sampai Ulama Nusantara, Jakarta: Kalam Mulia 2012. Untuk buku pendukung (sekunder) penulis menggunakan buku Badri Yatim, Sejarah Peradaban Islam Dirasah Islamiyah II, (Jakarta: Raja Grafindo Persada 2006)

\section{Hasil dan Pembahasan}

Pada zaman Rasulullah SAW, pendidikan Islam dilaksanakan pada dua periode, yaitu periode Makkah dan Periode Madinah. Periode Makkah sebagai fase awal pembinaan pendidikan Islam dan berpusat di Makkah, sedangkan periode Madinah sebagai fase lanjutan pembinaan pendidikan islam sekaligus sebagai pusat kegiatannya. Pelaksanaan pendidikan Islam akan diuraikan sebagai berikut.

\section{A. Pembinaan Pendidikan Islam di Makkah}

Sebagaimana diketahui bahwa Rasulullah SAW, diutus untuk menyempurnakan akhlak, dan misi ini merupakan misi pendidikan kenabian (pendidik propetik). Dengan akhlaknya yang terpuji, syarat dengan nilai-nilai humanism (insaniyah) dan spiritualisme (ilahiyah) di tengahtengah umat yang hampir saja tidak berperikemanusiaan, Nabi Muhammad Saw mendapat gelar tertinggi $A l$-Amin (Yatim, 2006). Perjalanan pembinaan pendidikan Islam pada masa nabi Muhammad Saw. dimulai dengan kepekaan nabi Muhammad Saw. terhadap kondisi sosiokultural dan politik yang dilanjutkan dengan sesuatu proses mempertahankan tradisi nabi Ibrahim yaitu tabah dalam mencari kebenaran yang hakiki, menjauhkan diri dari keramaian dan sikap hedonisme dengan berkontemplasi ( ber-tahanus) di Gua Hira'. Maka, pada tanggal 17 Ramadhan turunlah wahyu pertama surat al- Alaq 1-5 sebagai babak baru fase dimulainya pendidikan Islam di Makkah.

\section{Tahap pendidikan Islam}

1. Tahap Pendidikan Islam secara sembunyi-sembunyi

Sebelum Rasulullah memulai tugasnya sebagai Rasul, yaitu melaksanakan pendidikan terhadap ummatnya, Allah Swt telah mendidik dan mempersiapkannya untuk melaksanakan tugas tersebut secara sempurna, melalui pengalaman, pengenalan, serta perannya dalam kehidupan masyarakat dan lingkungannya (Ifendi, 2020). Nabi Muhammad Saw pada awal 
penyebaran Islam bertindak selaku pendidik dan dilakukan secara bertahap. Pada awal turunya wahyu pertama (the first revelation) surah ke 74 ayat 1-7, pola pendidikan yang dilakukan adalah secara sembunyi-sembunyi mengingat kondisi sosial politik yang belum stabil, dimulai dari dirinya dan keluarga dekatnya. Mula-mula Rasulullah mendidik istrinya Khadijah untuk beriman dan menerima petunjuk Allah, kemudian diikuti oleh anak angkatnya Ali bin Abi Thalib dan Zaid bin Haritsah. Kemudian sahabat karibnya Abu Bakar Shiddiq. Secara berangsur-angsur ajakan tersebut disampaikan secara meluas, tetapi masih terbatas di kalangan keluarga dekat dari suku Quraisy saja, seperti Usman Bin Affan, Zubair Bin Awwam, Saad Bin Abi Waqas, Abdurahman Bin Auf, Thalhah Bin Ubaidillah, Abu Ubaidillah Al Jarrah, Arqam Bin Abi Arqam Fatimah Binti Khattab, Said Bin Tsabid, dan beberapa orang lainnya mereka semua disebut Assabiquna Awwalun.

Kegiatan pendidikan diselenggarakan di rumah-rumah sahabat, yang paling terkenal adalah Dar al-Arqam sebagai derivasi langsung dari nama sahabat pemilik rumah yang dijadikan tempat pembelajaran antara Rasulullah saw dan umat Islam (Suriadi, 2020).

Dari pemaparan diatas dapat kita pahami bahwa sebelum Allah memerintahkan nabi untuk memberikan pendidikan kepada umatnya terlebih dahulu Allah memberikan pelajaran kepada Nabi SAW setelah itu baru diperintahkan untuk memberikan pendidikan islam kepada ummatnya. Pendidikan Islam mulanya dilakukan secara sembunyi-sembunyi di rumah Arqam bin Abil Arqam yang gunanya agar orang-orang kafir Quraisy tidak mengetahui bahwa Pendidikan Islam yang disampaikan Nabi SAW telah berlangsung juga untuk keamanan para sahabat yang pertama belajar dengan Rasulullah SAW. dan juga atas perintah Allah swt agar berdakwah secara sembunyi-sembunyi.

\section{Tahap Pendidikan Islam secara terang-terangan}

Setelah kurang lebih selama 3 tahun Rasulullah SAW berdakwah dan mendidik secara sembunyi-sembunyi untuk orang-orang terdekat di Dar al-Arqam barulah kemudian turun Firman Allah dalam surat al- Syu'ara: 214-215:

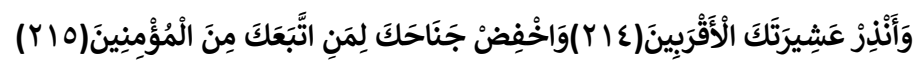

Artinya: Dan berilah peringatan kepada kerabat-kerabatmu yang terdekat, dan rendahkanlah dirimu terhadap orang-orang yang mengikutimu, Yaitu orang-orang yang beriman.

Dengan turunnya perintah tersebut, maka Rasulullah mulailah memberikan pelajaran kepada umatnya secara terbuka dan lebih luas lagi, bukan hanya untuk orang terdekat namun juga seluruh penduduk Makkah terutama mereka yang datang ke Makkah, baik yang sedang melaksanakan ibadah haji maupun berdagang. Perintah berdakwah secara terang-terangan dilakukan oleh Rasulullah seiring jumlah sahabat yang semakin banyak dan untuk meningkatkan jangkauan seruan dakwah, karena diyakini dengan dakwah tersebut banyak kaum Quraisy yang akan masuk Islam. Disamping itu keberadaan rumah Arqam bin Abi Arqam sebagai pusat lembaga pendidikan Islam sudah diketahui Quraisy (Ramayulis, 2011).

\section{Tahap pendidikan secara umum}

Hasil seruan secara terang-terangan yang berfokus kepada keluarga terdekat kelihatan nya belum maksimal sesuai dengan apa yang diharapkan. Maka, Rasulullah mengubah seruan dakwahnya menjadi berfokus kepada umum, umat manusia secara keseluruhan. Seruan dalam skala internasional tersebut didasarkan perintah Allah surah Al Hijr ayat 94.

$$
\text { فَاصْدَعْ بِمَا تُؤمَرُ وَأَعْرِنْ عَنِ الْمُشْرِكِينَ }
$$

Artinya: Maka sampaikanlah olehmu secara terang-terangan segala apa yang diperintahkan (kepadamu) dan berpalinglah dari orang-orang yang musyrik.

Setelah perintah Allah ini sampai kepada Rasulullah SAW. maka beliau menyeru dan mengajak seluruh lapisan masyarakat untuk masuk Islam, baik ia orang kaya, bangsawan, hamba sahaya, orang miskin, maupun pedagang baik mereka orang-orang Makkah maupun luar Makkah. Pada setiap musim haji Rasulullah SAW. mengunjungi kemah-kemah jemaah haji membicarakan masalah agama dan menyampaikan seruan Islam kepada mereka. Namun, 
tidak semua jamaah yang didatangi Rasulullah menerima ajakan nabi untuk masuk Islam, kecuali sekelompok jamaah haji dari Yastrib yaitu kabilah Khazraj. Peristiwa ini merupakan titik balik dari misi Nabi Muhammad SAW. beliau mempunyai tumpuan harapan yang cerah dari ummat nya yang telah memiliki kesiapan mental untuk menerima dan menyebarluaskan ajaran-ajaran Islam di negerinya (B, 2013).

\section{Materi Pendidikan Islam}

Materi pendidikan Islam di Makkah terbagi kedalam dua bagian, yaitu: pertama, materi pendidikan tauhid, materi ini lebih difokuskan untuk memurnikan ajaran tauhid yang dibawa Nabi Ibrahim yang telah diselewengkan oleh masyarakat jahiliyah. Secara teori inti sari ajaran tauhid terdapat dalam kandungan surah Al Fatihah 1-7 dan surah Al Ikhlas ayat 1-4.

Secara praktis pendidikan tauhid diberikan melalui cara-cara yang bijaksana, menuntun akal pikiran dengan mengajak umatnya membaca, memperhatiakn dan memikirkan sendiri kekuasaan dan kebesaran Allah dan diri manusia itu sendiri. Kemudian beliau mengajarkan cara bagaimana mengaplikasikan pengertian tauhid dala kehidupan sehari0hari. Rasulullah menjadi contoh bagi umatnya. Hasilnya, kebiasaan masyarakat Arab yang perbuatan atas nama berhala diganti dengan dengan ucapan bismillahirrahmanirrahim. Kebiasaan menyembah berhala diganti dengan mengagungkan Allah SWT (Hafiddin, 2015). Kedua, materi pengajaran Al-Qur'an. Materi ini dapat dirinci sebagai berikut:

1. Materi baca tulis Al-Qur'an

2. Materi menghafal Al-Qur'an

3. Materi memahami Al-Qur'an

Materi pendidikan Al-Qur'an yang tersebut pada masa nabi berada di Makkah di laksanakan di Kuttab.Kuttab berasal dari kata kataba yang berarti menulis atau tempat menulis. Selanjutnya, pembinaan pendidikan Islam di Makkah meliputi:

1. Pendidikan Keagamaan

2. Pendidikan aqliyah dan ilmiah

3. Pendidikan Akhlak dan Budi Pekerti

4. Pendidikan Jasmani (Nasution, 2012).

\section{Metode Pendidikan Islam}

Metode pendidikan yang dilakukan oleh Rasulullah dalam mendidik sahabatnya antara lain: a) metode ceramah, b) dialog, c) diskusi atau tanya jawab, d) metode perumpamaan, e) metode kisah, f) metode pembiasaan, g) metode hafalan agar Al-Qur'an terjaga kemurniannya dengan hafalan sahabat (Husein, 2018). Kalau kita bawakan ke pendidikan sekarang metodemetode pendidikan yang telah ada dan berkembang merupakan lanjutan metode yang dahulu telah diterapkan Rasulullah untuk mendidik umatnya dengan metode tersebut rasulullah saw bisa membawa umat yang dulunya jahiliyah kepada umat yang tau akan Tuhan yang sebenarnya, begitu juga hendaknya dengan melanjutkan metode mengajar yang Rasulullah ajarkan diharapkan peserta didik saat ini juga bisa mengembangkan potensi yang ada dalam dirinya dengan sebaik-baik mungkin tentunya sesuai syariat Allah dan Rasul-Nya.

\section{Kurikulum Pendidikan Islam}

Kurikulum pendidikan Islam pada periode Rasulullah baik di Makkah maupun di Madinah adalah Al-Qur'an yang Allah wahyukan sesuai dengan kondisi dan situasi, kejadian dan peristiwa yang dialami umat Islam pada saat itu, karena itu dalam praktiknya tidak saja logis dan rasional, tetapi juga fitrah dan pragmatis. Hasil cara yang demikian dapat dilihat dari sikap rohani dan mental para pengikutnya. Oleh karena itu rumusan dan materi pendidikan, sekitar 14 abad yang lalu menggambarkan Rasulullah menerapkan kurikulum berbasis masyarakat (Suriadi, 2020). 


\section{Lembaga Pendidikan}

Lembaga pendidikan di zaman rasulullah saw. adalah tempat berlangsungnya proses pendidikan, berikut lembaga pendidikan Islam masa Rasulullah Saw:

1. Rumah, selain di rumah Arqam bin Arqam pendidikan juga dilakukan dirumah rasulullah secara langsung. Di sinilah Rasulullah SAW. mengajarkan dasar-dasar atau poko-pokok agama Islam kepada shabat-sahabatnya, di sini pula Nabi SAW membacakan ayat-ayat suci Al-Qur'an kepada pengikut-pengikutnya, menerima tamu dan orang-orang yang hendak memeluk agama Islam dan menanyakan hal-hal yang bersangkut paut dengan agama Islam (Mahmud, 1990).

2. Masjid, pendidikan Islam erat kaitnnya dengan masjid. Kaum muslimin telah memamfaatkan masjid untuk tempat ibadah da sebagai lembaga pendidikan keagamaan yang dipelajari kaidah-kaidah Islam, hukum-hukum agama dan sebagainya. masjid pertama yang didirikan Rasulullah SAW. adalah masjid Quba di luar kota Madinah.

3. Kuttab, (tempat sekolah anak-anak), sudah ada di Arab sebelum Islam datangnamun belum dikenal luas di masyarakat, kuttab ini awalnya sebagai tempat menulis dan membaca. Setelah islam datang kuttab dijadikan sebagai tempat mempelajari Al-Qur'an (Ifendi, 2021).

\section{B. Pembinaan Pendidikan Islam di Madinah}

Hijrah dari Makkah ke Madinah bukan hanya sekedar berpindah dan menghindar dari tekanan dan ancaman kaumkafir Quraisy dan pendudk Makkah yang tidak menghendaki pembaharuan terhadap ajaran nenek moyang mereka, tetapi juga mengandung maksud untuk mengatur formasi dan menyusun kekuatan dalam mengahdapi tantangan-tantangan lebih lanjut, sehingga akhirnya nanti terbentuk masyarakat baru yang didalamnya bersinar kembali mutiara tauhid warisan Ibrahim yang disempurnakan Nabi Muhammad SAW. melalui wahyu (Ifendi, 2021).

Kedatangan Nabi bersama kaum Muslimin dari Makkah, disambut hangat oleh penduduk Madinah dengan gembira dan penih rasa persaudaraan. Maka Islam mendapatkan lingkungan yang memungkinkan bagi Nabi saw untuk meneruskan dakwahnya, menyampaiakn ajaran Islam dan menjabarkannya dalam kehidupan sehari-hari. Oleh karena itu pada fase Makkah ciri pokok pembinaan pendidikan adalah tauhid maka di fase Madinah dapat dikatakan sebagai pendidikan politik sosial.

\section{Lembaga Pendidikan Islam}

Setelah Rasulullah saw. hijrah ke Madinah, pendidikan Islam dijalnkan secara leluasa, sistematis, dan terstruktur dengan mendirikan beberapa lembaga pendidikan. Langkah pertama yang dilakuka Rasulullah adalah mendirikan masjid sebagai sentral tempat ibaah dan mengatur kehidupan umat Islam dengan petunjuk ajaran Islam.Masjid disamping tempat ibadah juga metupaka tempat mengajarkan ilmu-ilmu keagamaan. Bagi anak-anak Islam, Rasulullah saw. mendirikan Kuttab sebagai pusat pendidikan dalam hal membaca dan menulis (B, 2013). Secara teknis proses pendidikan islam pada periode ini tidak hanya dilakukan oleh kaum muslimin tapi juga oleh para tawanan perang meskipu mereka belum Islam. Dengan kemampuan membaca dan menulis yang mereka miliki diberikan tanggung jawab oleh Rasulullah untuk melaksanakan pendidikan bagi anak-anak muslim sebagai tebusan pembebasan mereka sebagai tawanan perang.

\section{Materi Pendidikan Islam}

Pada masa ini materi pendidikan yang diberikan cakupannya lebih luas dan kompleks diantaranya yaitu:

a. Pendidikan ukhuwah.

b. Pendidikan kesejahteraan sosial. 
c. Pendidikan kesejahteraan keluarga kaum kerabat.

d. Pendidikan hankam (pertahanan dan keamanan).

Selain yang disebutkan di atas materi pendidikan yang diberikan Nabi SAW.yaitu, bidang keimanan, peribadatan, muamalah, bidang akhlak, kesehatan, bidang politik, bidang ekonomi, sosial, budaya, serta ajaran-ajaran yang mencakup aspek kehidupan manusia (Hafiddin, 2015). Jadi secara keseluruhan pendidikan Islam periode Makkah dan periode Madinah sama, namun cakupan dalam materi jadi lebih luas di Madinah dibandingkan di Makkah, karena di Madinah tidak ada tekanan dari siapapun sehingga Nabi saw dengan leluasa untuk mengembangkan ajaran Islam di Madinah.

\section{Keberadaan Masjid Dan Kuttab Dalam Pengembangan Pendidikan Islam}

\section{Institusi Pendidikan Masjid}

Pada periode awal pendidikan islam yaitu pada masa Rasulullah saw. masjid memiliki peranan signifikan dan strategis, baik ketika di Makkah maupun di Madinah. Masjid Quba ini merupakan tempat peribadatan umat Islam yang kemudian menjadi model dalam pembangunan masjid-masjid lain di kemudian hari. Masjid Quba disamping menjadi tempat ibadah namun juga berfungsi sebagai tempat pendidikan dan pengajaran agama Islam, begitu juga dengan masjid nabawi yang merupakan mesjid nya Rasulullah SAW.pada saat ini pun masjid masih menjadi sentral pendidikan agama, apalagi kita di Minangkabau juga sangat erat kaitan dengan masjid baik bidang agama maupun masalah kehidupan sehari-hari (Suriadi, 2020). Keberadaan Masjid masa Rasulullah tidak hanya berfungsi sebagai tempat ibadah tetapi juga berperan sebagai tempat pendidikan. Apalagi di Indonesia khusunya di Minangkabau surau merupakan tempat sentral pendidikan dan urusan umat, seperti mempelajari Al Qur'an, bermusyawarah terkait keadaan ummat, belajar silat dan lain-lain.

\section{Institusi Pendidikan Kuttab}

Dengan datangnya Islam kegiatan pendidikan yang sudah ada sebelumnya dapat berkembang dengan baik. Perkembngan pendidikan pada masa ini tidak terlepas dari besarnya perhatian Al-Qur'an pada pendidikan juga kebijak-kebijakan yang diambil oleh rasulullah saw untuk umatnya. Penyelenggaraan pendidikan di kuttab, awalnya hanya dirumah para guruguru atau di perkarangan masjid.Kuttab-kuttab tersebut juga sering merupakan wakaf dari orang-orang kaya untuk anak-anak yang tidak mampu secara gratis dan tidak dipungut biaya sepeserpun.

Keberadaaan kuttab dan masjid merupakan salah satu bentuk keluwesan Islam dalam mengadopsi nilai-nilai positif dari tradisi lama pada masa awal pertumbuhan Islam. Kuttab merupakan bentuk dari adaptasi tradisi pra Islam dan masjid merupakan lembaga pendidikan islam yang sui generis. Lahir dari rahim Islam sendiri yang pada masa awal menjadi institusi sentral dan basis utama bagi pendidikan keumatan.Kelahian institusi-institusi selanjutnya adlah kelanjutan dari sistim pendidikankuttb dan masjid (Suriadi, 2020). Kuttab kalau kita realisasikan pendidikan Islam saat ini adalah lembaga pendidikan seperti Madrasah, kampus Islam dan lain-lain, yang semua itu merupakan realisasi kuttab di masa lalu. Kuttab masa Rasulullah hanya berada di rumah guru-guru tapi sekarang sudah berkembang menjadi Madrasah dengan gedung-gedung yang bertingkat dan segala fasilitas yang ada di dalamnya guna menunjang pendidikan Islam yang lebih baik lagi.

\section{Implikasi Dengan Pendidikan Islam Saat Ini}

Jika dikaji secara mendalam pelaksanaan dan sistem pendidikan islam masa Rasulullah SAW. ada bebrapa hal yang perlu dikemukakan sebagai bahan pertimbangan dalam melaksanakan pendidikan Islam dewasa ini, antara lain:

1. Materi pendidikan yang disampaikan Rasulullah SAW, disesuaikan dengan kondisi orangorang yang dihadapinya sehingga materi yang diajarkan mudah dicerna, dimengerti dan diamalkan, juga disesuaikan dengan kebutuhan masyarakatlingkungannya. Misalnya, ketika beliau di Makkah menghadapi orang-orang musyrik dengan akhlak yang buruk, 
maka materi pembelajaran agama ditekankan oleh beliau dalam masalah aqidah, menanamkan dalam hati mereka bahwa Tuhan itu satu, Maha Esa yaitu, Allah SWT, dan membentuk pribadi-pribadi berakhlak terpuji. Dalam satu riwayat dijelaskan bahwa ketika Nabi ditanya tentang amal-amal yang paling afdhal yang harus dilakukan maka Rasulullah menjawab dengan jawaban yang berbeda sesuai dengan kondisi masing-masing orang yang bertanya.

2. Lembaga pendidikan tempat Rasulullah mengajarkan agama Islam adalah lembaga informal (rumah tangga), dan non formal (Masjid), belum dijumpai lembaga pendidikan formal seperti sekolah atau madrasah. Namun demikian pendidikan Islam yang dilaksanakan oleh Rasulullah SAW, berhasil dengan baik.

3. Pendidik di zaman Rasulullah SAW, tidak mengharapkan imbalan jasa berupa gaji dan pemberian lainnya, tetapi semata-mata mengharapkan ridha Allah swt, mereka menjalankan tugasnya dengan penuh keikhlasan.

4. Materi pembelajaran yang diajarkan tidak terbatas pada masalah-masalah keagamaan tetapi juga masalah sosial kemasyarakatan seperti: hukum, pertahanan, keimanan, dan ekonomi atau perdagangan. Karena itu umat Islam dewasa ini diharapkan untuk tidak hanya mendalami pengetahuan-pengetahuan agama saja tapi juga pengetahuanpengetahuan umum lainnya.

5. Kesuksesan Rasulullah SAW. dan sahabat-sahabatnya mencapai tujuan pendidikan Islam karena apa yang diajarkan oleh beliau dan shabat-sahabatnya diamalkan dengan baik dalam kehidupan, beliau mencontohkan dalam wujud perbuatan sehari-hari.

6. Metode pembelajaran yang digunakan Rasulullah SAW, banyak merujuk pada wahyu yang diturunkan kepada beliau dan digunakan secara bervariasi, sehingga terhindar dari rasa bosan.

\section{Kesimpulan}

Pokok pembinaan pendidikan Islam di kota Makkah adalah pendidikan tauhid, titik beratnya adalah menanamkan nila-nilai tauhid ke dalam jiwa setiap individu muslim, agar terpancar sinar tauhid dan tercermin dari perbuatan dan tingkah laku dalam kehidupan seharihari. Pokok pembinaan Pendidikan Islam di Madinah dapat dikatakan sebagai pendidikan sosial politik yang merupaka kelanjutan dari pendidikan tauhid di Makkah, yaitu pembinaan di bidang sosial dan politik yang merupakan cermin dan pantulan sinar tauhid tersebut. Kuttab dan dan masjid sebagai lembaga awal pembinaan pendidikan islam memiliki peran yang begitu vital dalam sejarah pendidikan Islam. Kuttab dan Masjid menjadi tempat sentral pendidikan Islam pada masa lalu yang merupakam cikal bakal lahirnya institusi-institusi yang lainnya.

\section{Daftar Kepustakaan}

Amar, R. (2007). Pengantar Metodologi Penelitian. Hayfa Press.

B, C. (2013). Pendidikan Islam Masa Rasulullah. Diskursus Islam, 1(3).

Hafiddin, H. (2015). Pendidikan Islam Masa Rasulullah. Tarbiya, 1(1).

Husein, S. (2018). Pola Pendidikan Islam Masa Rasulullah (Kajian Historis Pendidikan Islam Masa Rasulullah Saw Fase Makkah Dan Madinah Serta Kontribusi Pada Pendidikan Islam Masa Kini). Jurnal Pendidikan Islam, 2(2).

Ifendi, M. (2020). Masa Pembinaan Pendidikan Islam: Telaah Kritis Pendidikan Rasulullah pada Periode Makkah. Jurnal Al-Rabwah, xiv(1).

Ifendi, M. (2021). Kuttab Lintasan Sejarah: Dari Masa Pembinaan Hingga Kejayaan Pendidikan Islam. At-Ta'dib: Jurnal Ilmiah PAI, 13(1).

Mahmud, Y. (1990). Sejarah pendidikan Islam (IV). Hidakarya Agung.

Nasution, H. (2012). Pembaharuan dalam Islam. Raja Grafindo Persada. 
Ramayulis. (2011). Sejarah Pendidikan Islam: Napaktilas Perubahan Konsep Filsafat Dan Metodologi Pendidikanislam Dari Era Nabi Saw Sampai Ulama Nusantara. Kalam Mulia.

Suriadi. (2020). Pendidikan Islam Masa Rasulullah. Jurnal Pendidikan Islam, 2(2).

Suwito, \& fauzan. (2008). Sejarah Sosial Pendidikan Islam. Prenada Media Group.

Yatim, B. (2006). Sejarah Peradaban Islam Dirasah Islamiyah II. Raja Grafindo Persada.

Zuhairini, \& dkk. (1986). Sejarah Pendidikan Islam. Depag RI 